\title{
Surface treatment comparison by application of diamond bur and Er,Cr:YSGG at different powers: morphological and mechanical evaluation
}

\author{
Mansoreh Mirzaie ${ }^{1}$, Esmael Yassini ${ }^{1}$, Ardavan Etemadi ${ }^{2}$, \\ Atefeh Tavakoli ${ }^{1}$, Nasim Chiniforush ${ }^{3}$ \\ 1: Restorative Dentistry Department, School of Dentistry, Tehran University of Medical Sciences, Tehran, Iran \\ 2: periodontics department, Azad University of Medical Sciences, Dental Branch \\ 3: PhD Candidate in Laser Dentistry, Laser Research Center of Dentistry, Dental Research Institute, \\ Tebran University of Medial Sciences, Tehran, Iran
}

\begin{abstract}
Purpose: This study evaluated the micro-tensile bond strength of new and previous composite resin restorations after surface treatment with diamond bur and Er,Cr:YSGG laser at different power settings (2,3 and $4 \mathrm{~W})$.

Materials and methods: Micro-hybride composite resin was inserted in metallic mold $5 \times 5 \times 15$ $\mathrm{mm}$ and cured for $40 \mathrm{sec}$ according to manufacturer's instruction.12 blocks were made. The bonded surfaces of the 12 blocks so obtained were subsequently ground using Silicon Carbide papers 1200 grit, for 15 seconds under running water.

Then the samples randomly were divided into 4 groups: (G1) Bur-treated, (G2) Er,Cr:YSGG laser with power of $2 \mathrm{~W}$ and energy of $100 \mathrm{~mJ}$, (G3) Er,Cr:YSGG laser with power of $3 \mathrm{~W}$ and energy of $150 \mathrm{~mJ}$, (G4) Er,Cr:YSGG laser with power of $4 \mathrm{~W}$ and energy of $200 \mathrm{~mJ}$.

One sample of each group was analyzed by SEM while, after cutting the blocks to $1 \mathrm{~mm}^{2}$ of area samples, the others samples were mechanically tested by Universal testing machine with the speed of $0.5 \mathrm{~mm}$ per minute till fracture point. Data were analysed using One-Way ANOVA and Tukey Test.

Results: T-test showed no significantly differences between G2 and G4(P=0.064) while G3 demonstrated significant differences than $\mathrm{G} 2(\mathrm{P}=0.001)$ and $\mathrm{G} 4(\mathrm{P}=0.000)$ and also between samples treated with bur (G1) and $\mathrm{G} 2(\mathrm{P}=0.242), \mathrm{G} 3(\mathrm{P}=0.000), \mathrm{G} 4(\mathrm{P}=0.829)$; $\mathrm{G} 1$ didn't significantly differ to $\mathrm{G} 2$ and $\mathrm{G} 4(\mathrm{P}>0.05)$, while $\mathrm{G} 1$ and $\mathrm{G} 3(\mathrm{P}<0.05)$.

Conclusion: On surface treatment of repaired composite, samples treated by laser at $3 \mathrm{~W}$ power showed better condition of micro-tensile bond strength.
\end{abstract}

Keywords: Microhybride composite $\cdot$ Er,Cr:YSGG laser • Bond strength

\section{Introduction}

Resin composite is a widely used material in direct restorative procedures. After a period of service, most resin restorations develop defects resulting from wear, fracture, or discoloration ${ }^{1)}$. Defective composite resin

\section{Addressee for Correspondence:}

Nasim Chiniforush PhD candidate of laser dentistry, Laser Research Center of Dentistry (LRCD), Dental Research Institute, Tehran University of Medical Sciences, Tehran, Iran Address: Dental Research Institute, Tehran University of Medical Sciences, Qouds Ave, Tehran, Iran. Postal code: 1441987566 , IR

Tel: 00989124949121 Fax: +98 2188850296

Email: n-chiniforush@farabi.tums.ac.ir restorations do not necessarily require complete removal. According to the minimally invasive restorative concept ${ }^{2}$ ), repairing may be considered to be the best choice for treatment. The repairing technique has some advantages like preservation of dental structures, inhibition of serious damage to the pulp tissues and lower costs 3 ).

Several techniques using mechanical and/or chemical treatments have been proposed to improve bonding quality. Examples of mechanical treatments to improve bonding area are bur abrasion, air abrasion

Received date: April 15th, 2016 Accepted: date: June 17th, 2016 
and laser application, while examples of chemical treatments are tribochemical silica coating with $30 \mu \mathrm{m}$ aluminum oxide, hydrofluoric acid, phosphoric acid, silane application, and application of a bonding agent $4,5)$.

Nowadays, the laser application in restorative dentistry causes less pain and reduce the need for anesthesia, increase bond strength.

The laser has many applications and much research has been done on it. Among different lasers using in dentistry, Erbium lasers are considered as the best option for caries removal and cavity preparation. This family has two wavelengths including Er:YAG laser (2940 nm) and Erbium, Chromium doped Yttrium Scandium Gallium Garnet (Er,Cr:YSGG) laser (2780 nm) ${ }^{6,7)}$.

Since there is not sufficient information regarding the effect of Er,Cr:YSGG laser as a surface treatment method on composite repair, the objectives of this study were to evaluate the surface treatment on the composite by application of different powers of Er,Cr:YSGG laser on its bond strength with microhybrid composite resin.

\section{Materials and methods}

\section{Sample preparation}

12 blocks of a micro-hybride (DiaFil TM, DiaDent, Korea), were made using a metallic mold with $5 \times 5 \times$ $15 \mathrm{~mm}$ dimensions. The composite resin was prepared with layering 1-mm-thick increments and each increment was cured for $40 \mathrm{sec}$ with a light curing device (Woodpecker, China), following manufacturer's instructions. The last increment compressed with a glass slide in order to obtain a flat surface for the specimen after light-curing. Subsequent to curing of the second layer, the specimens were removed from the mold. The bonding surface of these blocks were polished using 1200 grit silicon sandpaper for 15 seconds under running water to make an even surface.

Then the samples were randomly divided into 4 groups:

- Group 1 (GI): Bur-treated

- Group 2 (GII): Er,Cr:YSGG Laser irradiation with Power: 2 W, Energy:100mJ

- Group 3 (GIII): Er,Cr:YSGG Laser irradiation with power: $3 \mathrm{~W}$, Energy:150mJ

- Group 4 (GIV): Er,Cr:YSGG Laser irradiation with power: 4 W, Energy:200mJ

In group 1 , the composite surface was roughened by diamond fissure bur (D \&Z, Diamant, Germany) and rotating high speed handpiece with constant water spray, sweeping motion perpendicular to the surface with depth of $0.5 \mathrm{~mm}$. Then, the specimens were rinsed with distilled water and air-dried.

Laser preparation was performed with an Er,Cr:YSGG laser device ( WaterLase iPlus 2.0, Biolase CO, USA). All samples were prepared by MZ6 laser tip, a repetition rate of $20 \mathrm{~Hz}$, at $60 \%$ air and 30\% water level. The output power of this device was 2, 3, $4 \mathrm{~W}$ (energy density of $35.368,53.052,70.736$ ) in group 2, 3 , 4, respectively. The beam was aligned to be perpendicular to the target area, and was applied at a $1 \mathrm{~mm}$ distance during an exposure time of $10 \mathrm{sec}$; subsequently, the specimens were rinsed and air-dried.

One block of each group were analyzed with a scanning electron microscope at $\times 500, \times 1000, \times 2000$ and $\times 5000$ magnification in order to evaluate the surface texture created by the different powers of laser.

After surface treatment, in all of the groups, single-bottle adhesive resin (Adper TM Single Bond, 3M ESPE, Dental Products, St. Paul, MN, USA) was applied for $15 \mathrm{~s}$, then compressed with air for $5 \mathrm{~s}$ from $5 \mathrm{~cm}$ distances and cured for $10 \mathrm{~s}$ according to manufacturer's instructions. Then, the increment of $1 \mathrm{~mm}$ thickness of the same resin composite was applied to the treated resin composite blocks and light cured for $40 \mathrm{~s}$, composite layers were added till each block reached a height of $15 \mathrm{~mm}$. Next, the samples stored in incubator for $24 \mathrm{~h}$ at $37^{\circ} \mathrm{C}$ and $100 \%$ humidity.

\section{Micro-tensile bond strength test}

All of blocks mounted in Teflon mold with acrylic resin (Meliodent, Bayer, UK). Then, the blocks were sectioned using cutting machine (CNC, pars, Iran), so that 14 slabs in each group with cross section of about 1 mm were prepared.

The specimens were fixed on special jig of the micro-tensile bond strength device (Zwick, Germany). A crosshead speed of $0.5 \mathrm{~mm} / \mathrm{min}$ was used to debond the repaired surface interface. Micro-tensile bond strengths were recorded in Newtons and converted to mega pascals $(\mathrm{MPa})$. In order to determine failure modes, a stereomicroscope (Olympus SZX9; Olympus, Tokyo, Japan) was used at magnification $\times 30$. Failure mode was classified as follows: within composite area, within bonding area or interface between bonding and composite (mixed).

\section{Statistical analysis}

The data for bond strength were analyzed using oneway ANOVA. Pairwise comparisons were made by 
Tukey test. Statistical significance was set at $\mathrm{p}<0.05$.

\section{Result}

\section{Repair bond strength}

Repair bond strengths in MPa (means and standard deviations) for the groups are shown in Table 1. The GIII $(58.47+17.37)$ showed the highest bond strength and GIV (24.69+7.31) showed the lowest one.

There were statistically significant differences in bond strength among the groups $(\mathrm{p}<0.001)$. Multiple comparisons by Tukey's post-hoc tests (Table 2) showed no significant differences in bond strengths between G1, G2 and G4 ( $p>0.05$ ). Furthermore, significant difference were observed between G3 and the other groups $(\mathrm{p}<0.05)$.

The Mode of Failure

The mode of failure in all groups was shown in table 3

Table 1: means and standard deviations of all groups

\begin{tabular}{ll}
\hline group & Mean \pm Std. Deviation \\
\hline Bur (GI) & $27.4857 \pm 5.15794$ \\
$2 \mathrm{~W}(\mathrm{GII})$ & $34.4357 \pm 10.94311$ \\
$3 \mathrm{~W}(\mathrm{GIII})$ & $58.4714 \pm 17.37272$ \\
$4 \mathrm{~W}(\mathrm{GIV})$ & $24.6929 \pm 7.31547$ \\
\hline
\end{tabular}

The Chi-Square test showed no significant difference between the groups $(p=0.23)$.

\section{Scanning Electron Microscopic (SEM) Findings}

Under SEM evaluation in the laser groups, cleaned ablated surfaces with no smear layer production could be seen. The surfaces treated by Er,Cr:YSGG laser showed irregular and micro porous surfaces that by

Table 2: Multiple comparisons of all groups

\begin{tabular}{|c|c|c|}
\hline \multicolumn{2}{|c|}{ Groups } & Sig. \\
\hline \multirow{3}{*}{ bur } & $2 \mathrm{w}$ & .242 \\
\hline & $3 \mathrm{w}$ & .000 \\
\hline & $4 \mathrm{w}$ & .829 \\
\hline \multirow{3}{*}{$2 \mathrm{~W}$} & bur & .242 \\
\hline & $3 \mathrm{w}$ & .001 \\
\hline & $4 w$ & .064 \\
\hline \multirow{3}{*}{$3 \mathrm{~W}$} & bur & .000 \\
\hline & $2 \mathrm{w}$ & .001 \\
\hline & $4 \mathrm{w}$ & .000 \\
\hline \multirow{3}{*}{$4 \mathrm{~W}$} & bur & .829 \\
\hline & $2 \mathrm{w}$ & .064 \\
\hline & $3 \mathrm{w}$ & .000 \\
\hline
\end{tabular}

Table 3: Mode of Failure of all groups

\begin{tabular}{|c|c|c|c|c|c|c|}
\hline & & & \multicolumn{3}{|c|}{ mode of failure } & \multirow{2}{*}{ Total } \\
\hline & & & composite & bonding & mixed & \\
\hline \multirow{8}{*}{ group } & \multirow{2}{*}{ bur } & Count & 8 & 5 & 1 & 14 \\
\hline & & $\%$ within group & $57.1 \%$ & $35.7 \%$ & $7.1 \%$ & $100.0 \%$ \\
\hline & \multirow{2}{*}{$2 \mathrm{~W}$} & Count & 11 & 3 & 0 & 14 \\
\hline & & $\%$ within group & $78.6 \%$ & $21.4 \%$ & $0.0 \%$ & $100.0 \%$ \\
\hline & \multirow{2}{*}{$3 \mathrm{~W}$} & Count & 13 & 1 & 0 & 14 \\
\hline & & $\%$ within group & $92.9 \%$ & $7.1 \%$ & $0.0 \%$ & $100.0 \%$ \\
\hline & \multirow{2}{*}{$4 \mathrm{~W}$} & Count & 10 & 2 & 2 & 14 \\
\hline & & $\%$ within group & $71.4 \%$ & $14.3 \%$ & $14.3 \%$ & $100.0 \%$ \\
\hline \multirow{2}{*}{ Total } & & Count & 42 & 11 & 3 & 56 \\
\hline & & $\%$ within group & $75.0 \%$ & $19.6 \%$ & $5.4 \%$ & $100.0 \%$ \\
\hline
\end{tabular}


increasing the laser power, these changes also increased. (Figure 1-3). On the other hand, in group IV that prepared by bur, the noticeable smear layer was seen. (Figure 4)

\section{Discussion}

An ideal adhesive material should present no shrinkage during polymerization and have physicochemical properties similar to dental hard tissues ${ }^{8)}$. Some studies have shown that laboratory processed composites showed 25-80\% decrease in bond strength 9).

Previous researchers 10,11,12) reported that mechanical interlocking is the most significant factor contributing to repair strength. Increasing surface roughness provides better mechanical interlocking and enhances the probability of finding residual free carbon bonds throughout the surface area ${ }^{13}$ ).

Bonstein et al. ${ }^{14)}$ found that surface treatment with diamond burs resulted in higher bond strength compared to other surface treatments. However, several composite repair studies have shown that grinding of the composite resin surfaces leads to the formation of the smear layer ${ }^{10,15)}$.

In contrast to the bur, lasers ablate the restorative materials without smear layer formation ${ }^{16)}$. Due to the negative effect of smear layer on bonding, lasing is thought to provide a higher bonding strength than

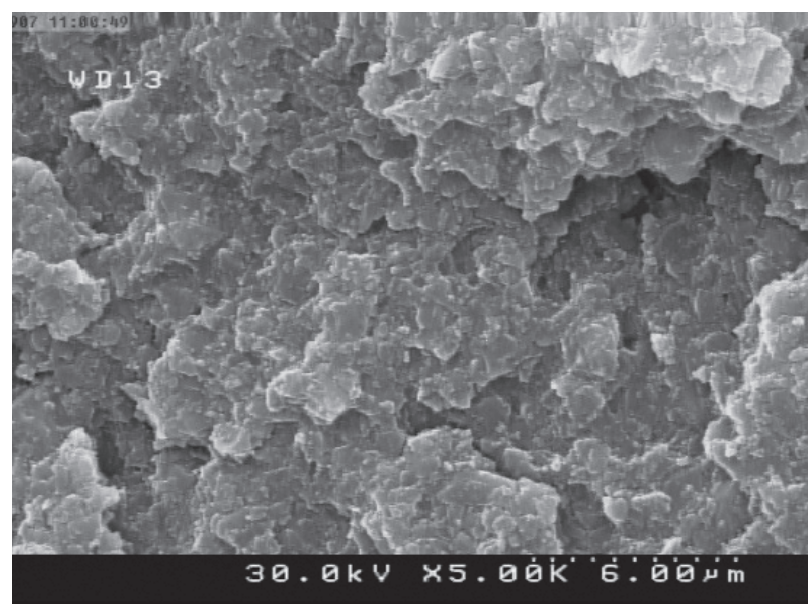

Figure 1: Surface treated by Er,Cr:YSGG laser with output power of $2 \mathrm{~W}$ (Original magnification $\times 5000$ )

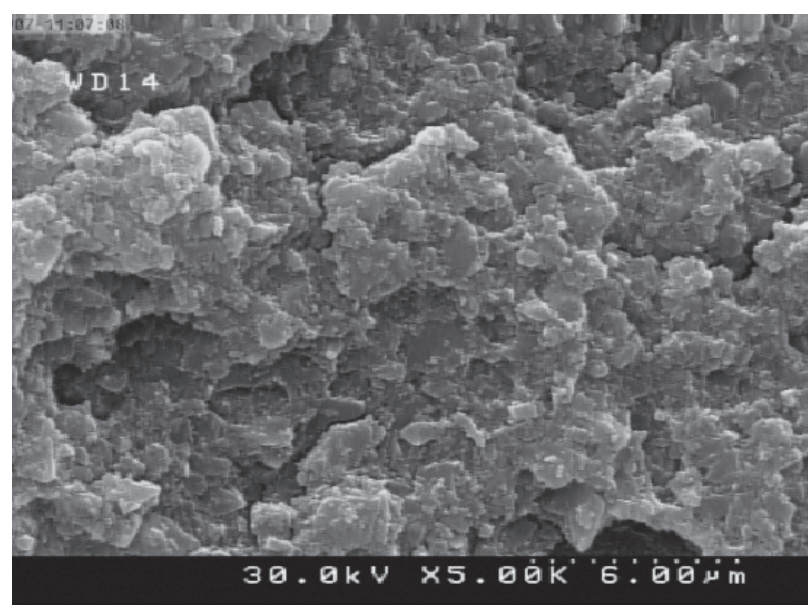

Figure 3: Surface treated by Er,Cr:YSGG laser with output power of $4 \mathrm{~W}$ (Original magnification $\times 5000$ )

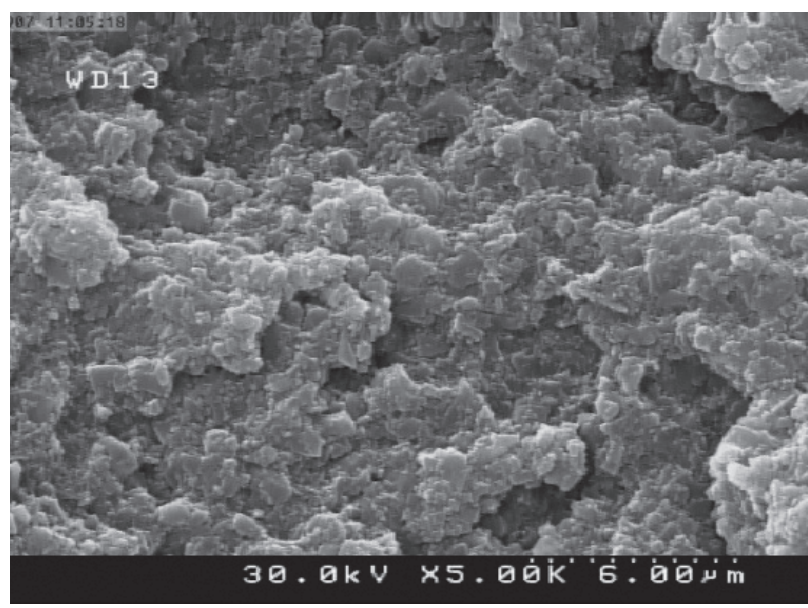

Figure 2: Surface treated by Er,Cr:YSGG laser with output power of $3 \mathrm{~W}$ (Original magnification $\times 5000$ )

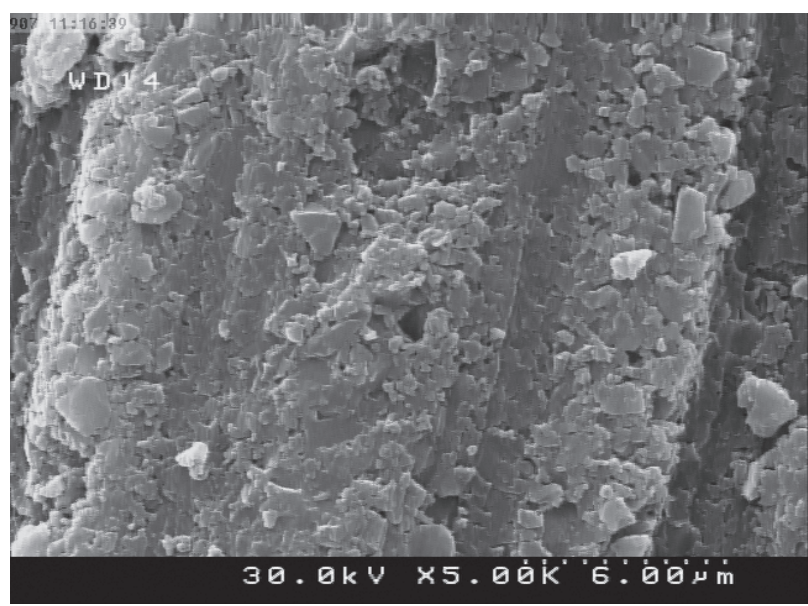

Figure 4: Surface treated by Bur (Original magnification $\times 5000)$ 
grinding with bur ${ }^{10)}$.

Rosatto et al. ${ }^{17)}$, compared the effect of diamond bur, air abrasion, and lasing on repair bond strength, found no significant difference between laser- and burtreated groups. These findings can be attributed to the acid etching procedure used in this study. The use of the acid etch on ground surfaces removes the smear debris, exposing the underlying surface and fillers ${ }^{15)}$.

Kimyai et al. ${ }^{10)}$ reported that Er,Cr:YSGG laser treated laboratory composite resulted in higher repair bond strength compared to diamond bur. The differences in findings of this study might be related to the type of composites used, given that the composition of composite resin can affect the efficacy of mechanical surface treatments 18,19 ).

Lizarelli et al. ${ }^{20)}$ investigated the ablation rate and morphological aspects of an Er:YAG laser on different types of composite resin, including microfiller, hybrid, and condensable. They found that the surface of ablated region was smoother for the hybrid composite than for others. The authors also claimed that the micro-morphological aspects, rate of penetration, and overall ablation rate were dependent upon the chemical composition and structure of the composite resin as well as the laser parameters.

An important point for laser studies is irradiation parameters. Previous researchers evaluated different energy parameters $(200 \mathrm{~mJ}, 300 \mathrm{~mJ}, 400 \mathrm{~mJ})$ in order to determine the best surface treatment in terms of com- posite repair bond strength ${ }^{17)}$. Despite the fact that there was no statistically significant difference among the experimental groups, $400 \mathrm{~mJ}$ of energy showed the lowest value of bonding strength. The authors reported that increasing energy in laser pulse did not seem to promote general aspects of change, but a larger modification occurred in the polymer. Additionally, higher laser power settings (400 and $600 \mathrm{~mJ}$ ) caused excessive material deterioration, making them unsuitable as surface treatments for dental materials surfaces ${ }^{21)}$.

Hence, in the present study, a lower power setting for the Er,Cr:YSGG laser was selected in accordance with the results of the preliminary investigation. In addition, the surfaces were irradiated with constant water cooling.

However, further investigations focusing on the effect of different laser parameters and clinical studies are necessary to develop guidelines for the repair of composite restorations with Er,Cr:YSGG laser or diamond bur.

\section{Conclusion}

Er,Cr:YSGG laser with output power of $3 \mathrm{~W}$ can be used as an alternative technique for surface treatment of unsatisfactory composite restorations. There is still need to do more researches to find the best protocol for achieving to the best bonding surface.

\section{References}

1: Mjor IA, \& Moorhead JE (1998): Selection of restorative materials, reasons for replacement, and longevity of restorations in Florida Journal of the American College of Dentists, 65(3) 27-33.

2: Murdoch-Kinch MA, McLean ME (2003): Minimally invasive dentistry. Journal of American Dental Association, 134:87-95.

3: Gordan VV, Mjor IA, Blum IR, Wilson N (2003):Teaching students the repair of resin-based composite restorations: a survey of North American dental schools. Journal of American Dental Association, 134:317-323.

4: Lewis: G, Johnson W, Martin W, Carnerdy A, Claburn C, Collier M (1998): Shear bond strength of immediately repaired light-cured composite resin restorations. Operative Dentistry, 23:121-127.

5: Oztas N, Alacam A, Bardaksy Y(2003): The effect of air abrasion with two new bonding agents on composite repair. Operative Dentistry, 28:149-154.

6: Fornaini C (2013): Er:YAG and adhesion in conservative dentistry: clinical overview. Laser Ther, 22(1):31-5.

7: Arami S, Shahabi S, Tabatabaie M, Chiniforush N, Morshedi E, Torabi S (2014): Assessing microleakage of composite restorations in class $\mathrm{V}$ cavities prepared by Er:YAG laser irradiation or diamond bur. Journal of Conservative Dentistry, 17:216-9

8: Türkmen C, Durkan M, Cimilli H, Öksüz M (2011): Tensile bond strength of indirect composites luted with three new self-adhesive resin cements to dentin. Journal of Applied Oral Sciences, 19(4):363-9.

9: Hasani Tabatabaei M, Alizade Y, Taalim S (2004): Effect of various surface treatment on repair strength of composite resin. Journal of Dentistry of Tehran University of Medical Sciences, 1(4): 17086.

10: Kimyai S, Mohammadi N, Navimipour EJ, 
Rikhtegaran S (2010): Comparison of the effect of three mechanical surface treatments on the repair bond strength of a laboratory composite. Photomedicine and Laser Surgery, 28(2):25-30.

11: Söderholm KJ, Roberts MJ (1991): Variables influencing the repair strength of dental composites. Scandinavian Journal of Dental Research, 99:173180.

12: Brosh T, Pilo R, Bichacho N, Blutstein R (1997): Effect of combinations of surface treatments and bonding agents on the bond strength of repaired composites. Journal of Prosthetic Dentistry, 77:122126.

13: Nilsoon E, Alaeddin S (2000): Factors affecting the shear bond strength of bonded composite inlays. International Journal of Prosthodontics, 13:52-58.

14: Bonstein T, Garlapo D, Donarummo J Jr, Bush PJ (2005): Evaluation of varied repair protocols applied to aged composite resin. Journal of Adhesive Dentistry, 7(1):41-49.

15: Fawzy AS, El-Askary FS, Amer MA (2008): Effect of surface treatments on the tensile bond strength of repaired water-aged anterior restorative micro-fine hybrid resin composite. Journal of Dentistry, 36 (12):969-976.

16: Lizarelli RF, Moriyama LT, Bagnato VS (2003):
Ablation of composite resins using Er:YAG lasercomparison with enamel and dentin. Lasers in Surgery and Medicine, 33(2):132-139.

17: Rossato D.M., Bandeca M.C., Saade E.G., Lizarelli R.F.Z., Bagnato V.S., Saad J.R.C (2009): Influence of Er:YAG laser on surface treatment of aged composite resin to repair restoration. Laser Physics, 19(11) 2144-2149.

18: Lucena-Martín C, González-López S, NavajasRodríguez de Mondelo JM (2001): The effect of various surface treatments and bonding agents on the repaired strength of heat-treated composites. Journal of Prosthetic Dentistry, 86:481-488.

19: Swift EJ Jr, Cloe BC, Boyer DB (1994): Effect of a silane coupling agent on composite repair strengths. American Journal of Dentistry, 7:200-202.

20: Lizarelli RFZ, Moriyama LT, Pelino JEP, Bagnato VS (2005): Ablation rate and morphological aspects of composite resins exposed to Er:YAG laser. Journal of Oral Laser Application, 5(3):151-160.

21: Cavalcanti AN, Pilecki P, Foxton RM, Watson TF, Oliveira MT, Gianinni M, Marchi GM (2009): Evaluation of the surface roughness and morphologic features of Y-TZP ceramics after different surface treatments. Photomedicine and Laser Surgery, 27(3):473-479. 